\title{
Female models in an American glamour website: geographic distribution, modeling limits and income according to their self presentations
}

\author{
Julián Monge-Nájera \& Karla Vega Corrales \\ Laboratorio de Ecología Urbana, Vicerrectoría de Investigación, Universidad Estatal a Distancia, 2050 San José, Costa Rica; \\ julianmonge@gmail.com, kantr.vega@gmail.com
}

Received 23-IV-2013 • Corrected 29-VII-2013 • Accepted 28-I-2014

\begin{abstract}
The American glamour modeling market is the largest in the world and GlamourModels is the main specialized website in the field. We analyzed the 368 profiles of American models published at the site through 2011. The mean age of the models was 27,6 years and they were taller and slimmer that the general female population of the country (mean values: height $1,68 \mathrm{~m}$, weight $54 \mathrm{~kg}$ and waist-to-hip ratio 0,73 ). From 2001 to 2011 the representation of models in the website expanded from the East to the Central and Western parts of the USA. The number of models in a state can be predicted from its total population size. The state with the most models was California, followed by Texas, New York and Arizona. Only six states were unrepresented at the website in 2011 and all were states with small populations and without large cities. Generally models preferred to work clothed, even if the approach in the clothed categories was more sexual than in the art nude categories. Models might be worried about how their work can affect their social acceptance. They find in glamour modeling a supplementary source of income that can be pursued along with other activities and that offers a relatively high pay.
\end{abstract}

KEY WORDS: modeling, glamour, geography, age, nudity, economy.

\section{RESUMEN}

El mercado estadounidense de modelos glamour es el más grande del mundo y GlamourModels es el principal portal especializado en ese campo. Analizamos los perfiles de 368 modelos estadounidenses publicados en el sitio hasta el 2011. Su edad promedio fue de 27,6 años y son más altas y esbeltas que la población femenina general del país (promedios: $1,68 \mathrm{~m}$ de altura, $54 \mathrm{~kg}$ y cociente cintura-cadera 0,73 ). De 2001 a 2011 la presencia de modelos en el sitio se expandió desde el este hasta las regiones central y occidental de los EE.UU. La cantidad de modelos producida por cada estado se puede predecir a partir de su población total. El estado con más modelos fue California, seguido por Texas, Nueva York y Arizona. Sólo seis estados seguían sin tener modelos en el sitio en 2011 y todos eran estados con poblaciones pequeñas y sin grandes ciudades. Generalmente las modelos prefieren trabajar vestidas aunque el enfoque sea más sexual que en el desnudo artístico. Puede preocuparles el rechazo social a este tipo de trabajo. Estas mujeres hallan en el modelaje glamour una fuente adicional de ingresos que se puede mantener en paralelo con otras actividades y que paga bien por hora.

PALABRAS CLAVE: modelos, glamour, geografía, edad, desnudez, economía.
Models are people who are presented as examples to imitate. For millennia they have served varied functions: models of religious behavior were used to sell relics in the Middle Ages; political models were used in propaganda by the Nazis and the Soviets in the $20^{\text {th }}$ century, and commercial models are used to sell all types of products today (Bock, 1983; Soley-Beltrán 2004).

Even though today's market requires a large variety of body types, as a rule models are expected to meet some beauty standards. Female models meet the Beauty Match-up Hypothesis: body shapes and facial characteristics match particular product lines (Solomon, Ashmore \& Longo, 1992). Unable to meet the often impossible beauty ideal presented by the media, women can suffer from low self esteem and health problems that include eating disorders like anorexia nervosa (Garner, Garfinkel, Schwartz \& Thompson, 1980).

Coy (2009) described how the media teaches girls that femininity and beauty are fundamental characteristics that they need for a good life and Soley-Beltrán (2004) wrote that the way models are selected is a form of visual neo-colonialism that values white women above others. Such criticisms were made even when normal women are told that models are not typical women and that they should accept their bodies as they are. This apparently positive message is considered by Frith, Raisborough 
and Sisterhood (2010) as just another capitalist technique, a form of "psychological rehabilitation" designed to make women feel better so that they consume more fashion and beauty products.

Independently of how women consider their differences with models, not all humans meet commercial beauty standards and this has important implications for survival, mating success, offspring production and parenting (Darwin, 1872; Buss, 2009). As a result of these implications, humans normally try to present a positive image of themselves, and is his classic work The Presentation of Self in Everyday Life, Goffman stated that the need for a positive "self presentation" turns everyone into a "social actor" (Goffman, 1959). Like theater actors, normal humans must both play and look the part, with the help of makeup, clothing, etc. (Bem 1967).

The subject was analyzed experimentally by Schlenker (1975) who found that, under public pressure, self-presentation is consistent with expectations of actual performance, and we now know that self-presentation affects scales used by psychologists to measure personality (Paulhus, Bruce \& Trapnell, 1995).

The lack of direct social clues in Internet gives people better control of how they present themselves to the public (Papacharissi, 2002) but there are surprisingly few studies on self presentation in the Internet (Schau \& Gilly, 2003; Coy \& Garner, 2010; Monge \& Vega, 2011; Turner, 2012).

While fashion models guide women about how they should present themselves to society and are ubiquitous in the media (Tovée, Mason, Emery, McCluskey \& CohenTovée, 1997), glamour models are not so well known and represent a different market segment. Glamour models do not help sell fashion or similar products; they normally model for art and soft-erotica photographers. Coy and Gardner (2010) wrote that the media turned glamour modeling into an acceptable occupation, and Monge \& Vega (2011) studied self presentation by glamour models in the early years of the Internet. Apparently these are the only studies available. In this article we revisit American glamour models, expand the scope of our previous study and compare some results with the panorama from a decade ago.

\section{METHODS}

The information in model websites is normally posted by the models themselves. The information basically consists of self descriptions about what the models look like, where they live, what kind of work they prefer, and what kind of modeling they reject. Less frequently they include information on their academic level, fees, contracts signed and personal data.

We decided to study Glamour Models (www.glamourmodels.com) because it is the largest specialized website for glamour models and because we had already done a study of the site with data from 2001 (Monge \& Vega, 2011). We collected our data in October 2011 and included the whole population of American models in the site (we excluded a small section with foreign models also available at the site).

Additionally to self descriptions, we recorded the state where each model lives (for an analysis of their geographic distribution) as well as the lists of modeling types that they prefer, and what kind of modeling they reject (for the identification of modeling limits). Additionally we recorded any information about fees and contracts listed in the profiles or in linked documents to estimate their annual income.

To compare with our current results, we reproduced the 2001 glamour models map from Monge \& Vega (2011). To check if total state population correlated with number of glamour models in the state we obtained the population size for each state from the official Census of the USA (http://www.census.gov/2010census/). We produced a correlation graph of state population versus number of models with the Alcula software (www.alcula. com/calculators/statistics/linear-regression/) and calculated significance with the Vassar Statistical Calculator (http://www.vassarstats.net/).

We also wanted to compare the body characteristics of the models with those of the general female population of the USA. For this, we used a computer-generated random sample of 70 profiles (from the total of 368 model profiles) to statistically analyze age, weight, height and waist-to-hip ratio (www.random.org/sequences/). We could not obtain biometric data for 2001 so this aspect is not compared for both periods.

Types of modeling are not defined by the website in its model signup for (http://glamourmodels.com/info/signup.html) so here they are defined according to Edelman (2013) and our own experience when Edelman did not provide details:

- Glamour: the model is presented with lightning, makeup and setting that make her appear elegant, beautiful and alluring. She may be clothed or seminude but covers the most intimate body parts.

- Fashion: the model is mostly dressed and displays clothing or other fashion items. 
- Art: the model presents the subjective intent of the photographer, which may range from a beautiful scene to a repulsive one; she may be clothed or semi-nude.

- Figure: modeling is done in the nude but darkness and poses cover the most intimate body parts.

- Acting: the model participates in storytelling by portraying a character, normally for a video recording, and this is mostly done fully clothed.

- Lingerie: the model poses in elegant undergarments.

- Nudes: the models poses in complete nudity but the nature of poses and lighting are not clearly predefined.

- Fetish: the model poses in clothes and with paraphernalia associated with sexual fetishism. May include sadomasochistic poses.

- Runway: the model walks in a narrow platform showing clothing and accessories.

- Erotic Nude: modeling is more focused in the sexual aspects of the female body but lighting and setting fit an artistic view.

- Video: the model moves in a erotic way, often seminude or nude, for videos that are produced in an artful way.

- Artistic Nude: the model poses nude to represent an artistic view that normally uses light to present the human body in an abstract way.

- Bondage: the model, nude or with erotic clothing, appears tied up, bounded or otherwise restrained (associated with sexual or aesthetic purposes).

- Web: the model acts in erotic ways that normally include nudity in front of a camera for live Internet transmission or recording. The content is openly sexual.

Ethics: our data were obtained from public profiles freely available in the Internet. The models did not intend to hide the kind of work they accepted or any other information we used in this study, and glamour models normally use pseudonyms rather than their real names. Nevertheless, we do not even include pseudonyms in this article.

\section{RESULTS}

A total of 368 models had profiles in the site when we extracted the data (2011). Their mean age was 27,6 years (Standard Deviation SD 6,7 years). Other mean measurements were: height $1,68 \mathrm{~m}(\mathrm{SD} 0,08 \mathrm{~m})$, weight $54 \mathrm{~kg}$ (SD $8,36 \mathrm{~kg}$ ) and waist-to-hip ratio $0,73(\mathrm{SD} 0,05)$.

\section{Geographic distribution}

Several patterns emerge when the geographic distribution of the models is mapped. In 2001 the models concentrated in the east coast, including an unexpected number of models from conservative states (Fig. 1). Ten years later, presence in the website had expanded to the Central and Western states. Rather than decreasing as a result of the conservative government of G. W. Bush (2001-2009), who was in office in the period between our two studies, the presence of conservative states in the website increased from 2001 to 2011 (Fig. 1). The state with most models was California (followed by Texas, New York and Arizona). All states with large cities had models. Furthermore, a statistical correlation analysis indicates that the number of models produced by a state can be predicted from its total population size (Fig. 2). The six states without models at the site have small populations and lack large cities: Delaware, Idaho, Mississippi, Montana, Oklahoma and Wyoming.

\section{Modeling limits}

The website includes a digital form in which the models must indicate which type of modeling they will do, from a pre-defined list. Most of them indicated that they would do Glamour modeling, as expected in a glamour site. Nevertheless, $10 \%$ failed to select the box for glamour and we do not know if this minority forgot to do so or actually meant that they would not accept this kind of work (Fig. 3). The second most selected category was fashion (Fig. 3), possibly the most desired category in modeling because it may pay high fees, but fashion is a category that these models often cannot enter because of their height (see Discussion).

As defined under Methods, the site also has several categories that imply nudity and Artistic Nude was the nude category with the highest acceptance level (Fig. 3). All these nude categories are not formally defined; in practice they may overlap, but more models chose the Figure category than Nude and Artistic Nude. Even though it is strongly sexual, the Fetish category had more acceptance than the Artistic Nude category (Fig. 3) perhaps because it is done clothed. The less accepted categories were Bondage and Web (Fig. 3).

Besides the quantitative data that we have analyzed in the previous section, a few models published comments that can be approached from a qualitative point of view. These comments dealt, among other topics, with how they felt about particular types of modeling and what limitations they had on the kind of work that they 


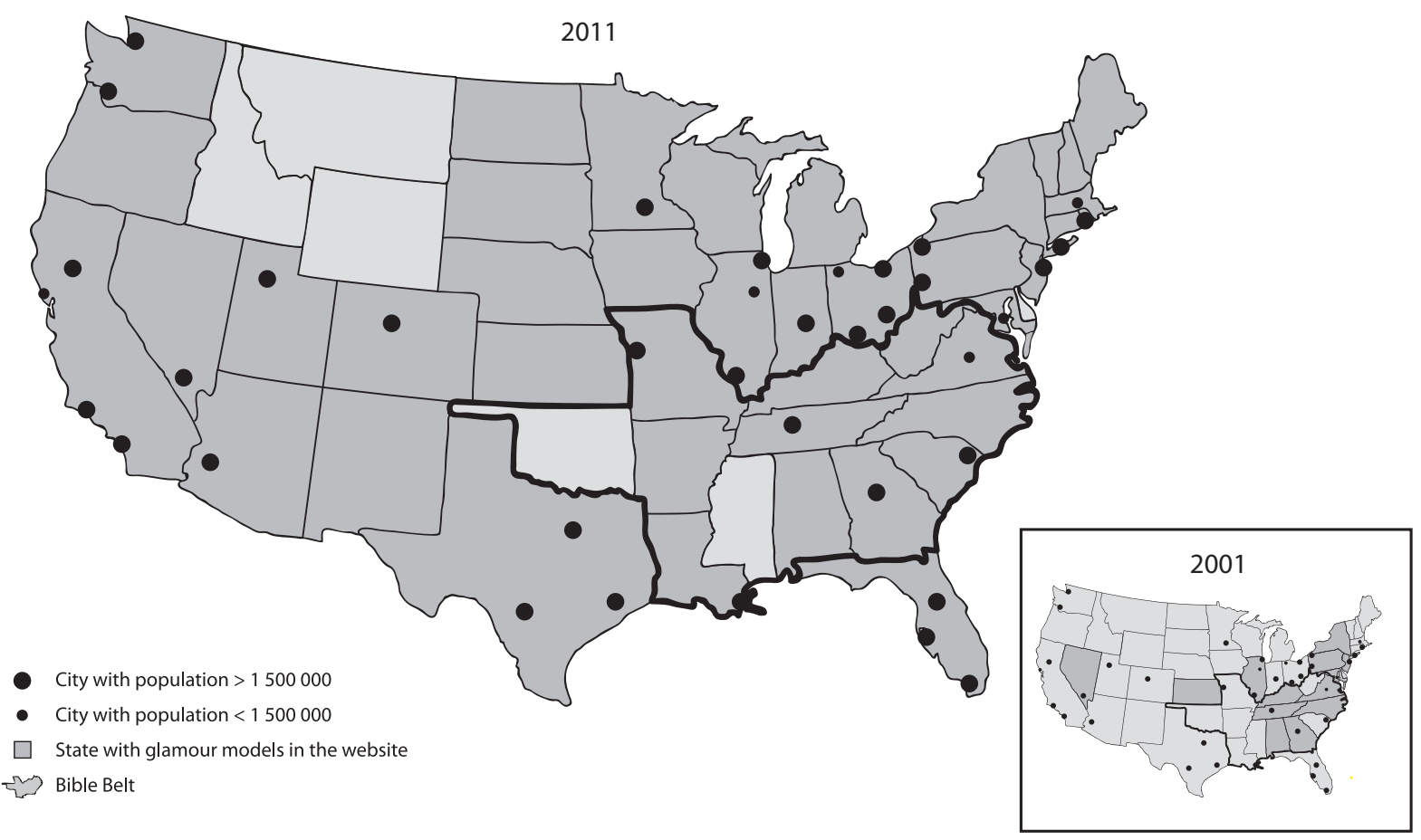

Fig. 1. Geographic distribution of glamour models in the USA according to profiles in GlamourModels.com, 2011 versus 2001. The circles represent large cities. The thick border line in the Southeast surrounds the most conservative states, known as the "Bible Belt". $\mathrm{N}=368$ models.

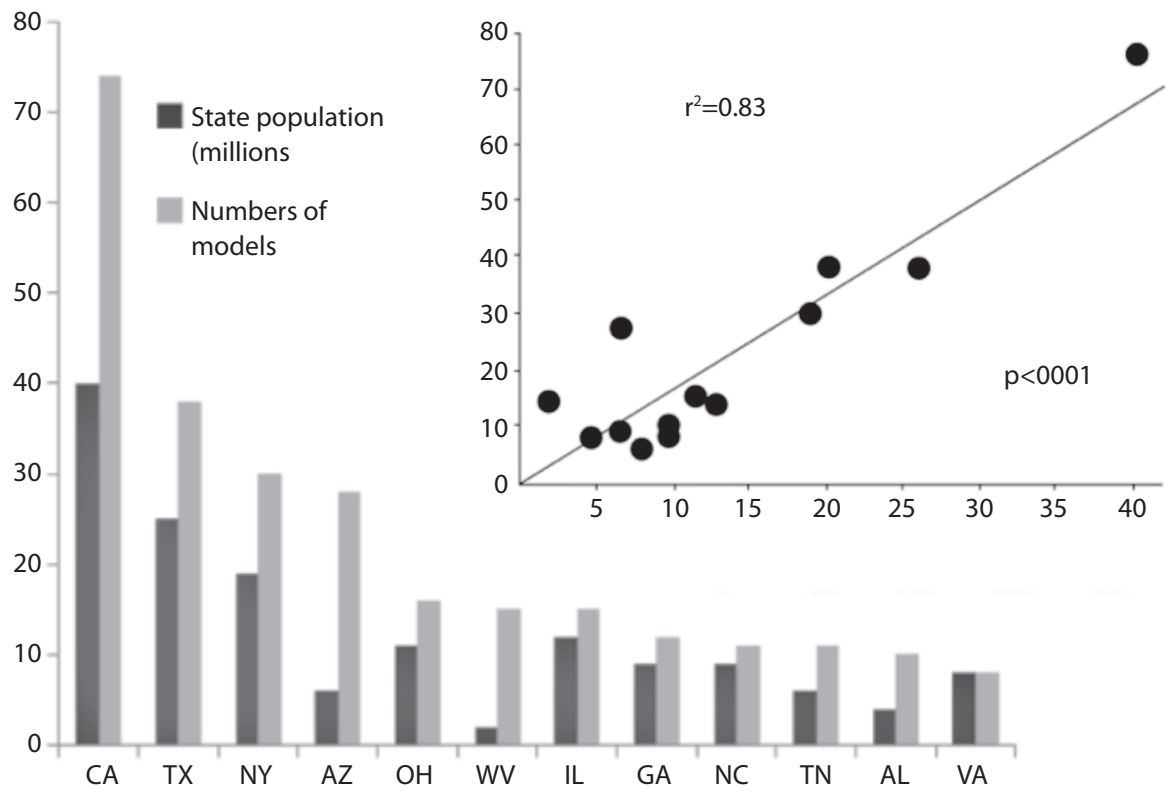

Fig. 2. State population (dark gray, in millions of inhabitants) and number of models (light gray, in total number) from the states with the largest number of models profiled in GlamourModels.com in 2011. Spearman Correlation Test, vertical axis number of models from that state, horizontal axis millions of inhabitants in the state. $\mathrm{N}=368$ models. 


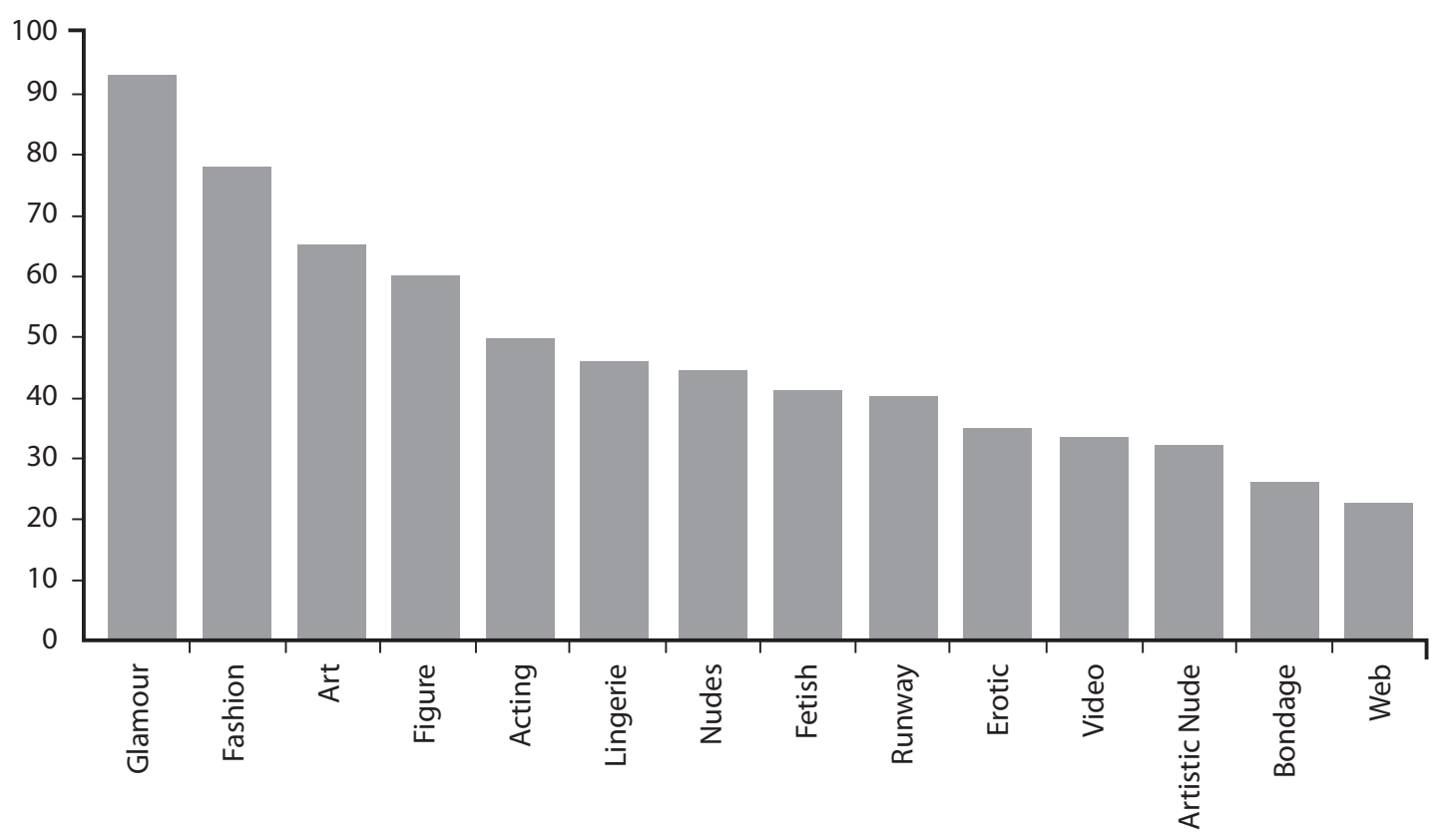

Fig. 3. Proportion of models (\%) that accept each type of modeling in the website GlamourModels. The missing bar part indicates the proportion of models that reject it, for example, Bondage and Web modeling are not accepted by most models. $\mathrm{N}=368 \mathrm{models}$.

accepted. We present representative comments, verbatim, in the next section.

\section{Examples of models' comments on work, motivation and limits}

A few models added texts stating that they were open to all the types of modeling described in the website. One wrote that sexually oriented modeling that is done clothed (Fetish, Bondage, Sadomasochism) was acceptable to her, while others stated that they preferred nude modeling even if paid only with digital copies of the photographs ("TFCD"). Some wrote that they would do posing that explicitly shows the vulva ("spreads") or that they accepted posing with another female model, which often has a sexual, lesbian connotation:

Fetish/bondage/alternative imagery is where my passion lies. However, I am available for just about any type of photoshoot you would want (model).

I'm into all types of modeling and always open to paid work, content sharing and TFCD. I am also completely comfortable with full nude (preferred) as well as fetish modeling (model).
I'm into all kinds of modeling, sounds vague but anything adult to bodypaint to fantasy looks like fantasy, fairy look etc. Photos that look like paintings, themes, etc. (model).

I accept a large range of work, but I am not limited to what I listed, and I am always looking for new projects and experiences; I DO NUDES and SOME PORN (PLEASE ENQUIRE) I do fetish, bdsm, erotic, and adult work (please enquire) I do shoot full nudes, including full spreads (model).

Others were very specific, repeating modeling types that the digital list already included, or provided a description of how they evolved with age in the kind of modeling that they would accept (one wrote that she moved from fashion in her adolescence to artistic nude when she became an adult); another stated that she was doing nude work while she still had a young body, apparently worried about how the human body changes with age. The previous cases do not mean that these models had no limits; for example one model wrote that she accepted erotic video work with other women but not with men, possibly influenced by how the resulting images might affect her social acceptance and even future romantic relationships. Finally, one showed her selfconfidence by stating that she was not afraid of a little 
ridicule and another expressed a strong artistic motivation, adding that she would do nudes as long as the results were original:

\section{WHAT I AM INTERESTED IN DOING AND NOT OPPOSED} TO: Swimsuit, video, portfolio updates, casual, head shots, fine art, tests, bridal, comic book, extras, calendar, promotional, two model shoot, lingerie, glamour, implied nudes, topless, parts model, glamour nude, artistic nude, figure nude, web work (model).

I have moved from shooting primary mainstream fashion in my teens, to mostly fine art, glamour, nude, and pinup inspired images now in my mid twenties (model).

I'm interested in doing nude photos and exotic films \& fetish films. I just think I'm young and this kind of modeling would be perfect considering my body is still young. And for videos I ONLY work with females (model).

My experience is in fetish, artistic nude, erotic, bikini and unique and fantasy photos. I love weird freaky ideas and different photo shoots. I am not afraid to look silly, will do nudes, bondage, fetish, lingerie, fashion, alternative, just ask. Also if ever looking for an actress, hit me up! (model).

I am open for tfp/cd. I am interested in glamour, nice headshot, casual, body paint, implied nudity, and some photos that are different, bold, sexy, and extravagant (model).

\section{Rejected types of modeling}

Some rejected unpaid nude modeling ("Trade for Photographs" or TFP), except if it could give them media exposure potentially leading to paid contracts. One explained that the reason for not posing in the nude was her "real job", again showing that the models can be aware of possible negative social repercussions of this line of work. Apparently some models are afraid of clients asking for sexual services so they openly stated that their services were limited to glamour posing and that they did not accept pornographic posing or provide sexual services. One model mentioned that she would not pose with men because of her sexual orientation; we ignore if that is the real reason but her statement is particularly interesting for its singularity, we did not find it in any other profile:

IDONOT shoot TFPor trade unless you are an internationally published, VERY well known photographer (model).

I will not consider offers for pornography. I will consider TFP on a very limited basis. TFP offers will be evaluated according to my need for certain types of images for my portfolio, creativity of the project, publication, and my available time. I will not accept TFP for nudes (model).

I can't do Nudes because of my real job. So please do not ask (model).

I am not shooting explicit projects or dancing or escorting! (model).

No nudity. Will not work with photographers who do not allow male escorts to accompany the models to the shoot. This is for safety purposes (model).

No offense to photographers, but I have 1000's of nude images already! I am NOT interested in romance. I am in a committed relationship and very much in love with my man. Please understand that these are photo shoots, not dates (model).

I don't do B/G. I am a lesbian (model).

\section{Income}

Some models published details on the academic degrees that they were pursuing and on the number of modeling contracts that they had signed. We used this information to assess their economic situation and income.

The studies were in varied fields, showing that there is no association between modeling for glamour photographers and pursuing a degree in a particular field: they listed Architecture; Biological Sciences; Broadcast News; Criminal Justice; Graphic Design and Business; Musical Performance and Acting; Web Design and Interactive Media; as well as two unidentified college degrees. Two models mentioned that they had graduated from modeling schools. The number of models mentioning higher studies was a very small fraction of the total population of the website. A total of 26 models published resumes with lists of contracts they had signed, and from these we calculated that they obtained a mean of 9,7 contracts per year.

Considering that normal glamour models can make at most $\$ 80$ per hour, and usually far less (www.modelsanctuary.com/html/guidelines.html, March 2, 2012) we estimate that on average they earned $\$ 2400$ per year from modeling (each session usually lasts 3 hours: $\$ 80 \times 3 \mathrm{hrx} 10$ contracts $=\$ 2400$ ). One quote summarizes the role that glamour modeling may play for them:

I'm working on getting my writing career underway. I'm modeling to make ends meet (model). 


\section{DISCUSSION}

The birth dates of the models indicate that, with a mean age of 28 years, many are in the typical age that American women finish their university studies and get married (www.census.gov/). The height of the models is $6 \mathrm{~cm}$ higher and their mean weight $21 \mathrm{~kg}$ lower than the average for the American female population (www. cdc.gov/nchs/fastats/bodymeas.htm). Their waist-to-hip ratio is 5 units lower than the ratio of the general female population (see Marlowe \& Wetsman, 2001). All these biometric data indicate that glamour models are taller and slimmer than the general population to which they belong, in agreement with ideas about female beauty that are widespread albeit still debated (Kościński, 2013). It seems obvious to us that these models do conform to a commercially acceptable idea of beauty and this explains why they work in this field.

\section{Geographic distribution}

The American glamour modeling market is the largest in the world and GlamourModels is the largest specialized website in the field. It has received more than 46 000000 model portfolio views in the last decade (http:// www.glamourmodels.com/newmodels.html). Our results show where the models live, what kind of work they do as well as what kind they do not accept.

One of the reasons why some women choose glamour modeling is that this work can become a supplementary source of income that can be pursued along with other activities and that pays well (Coy \& Garner, 2010). Considering that the adult female population of the USA in 2011 was around 313000000 (www.census.gov) and even assuming that only one in a 100 models posted their information in Glamour Models (368X100/313 $000000=0,017 \%$ ), it is clear that less than $0,02 \%$ of the female population does this kind of work, a very low number when compared to more common female occupations such as secretary, which for the year 2010 was the occupation of $1,23 \%$ of the female population (www.census.gov).

Why so few women work in glamour modeling can be explained by at least two reasons: the need to have certain physical characteristics, which few have, and the social rejection of a line of work that centers on body attractiveness (Coy \& Garner, 2010), which makes this activity undesirable in many social environments. A question that we suggest to future researchers is why some women chose modeling while their sisters do not. The use of sisters as controls would prevent the methodological error that afflicts so many studies about why people do work related with eroticism and sexuality (see Schifter, 1999).

The unexpected result that conservative states were among the first to produce glamour models posting their profiles in GlamourModels could be explained by the fact that not all people living in conservative states are conservatives, but this does not explain why many non-conservative states took longer to enter the site database. We propose two hypotheses for future testing: that entering the field of glamour modeling reflects a rebellious rejection of religious limitations imposed on women, and that women from conservative states have a lower academic level that makes the high profit per hour rates of modeling more attractive. These hypotheses are inspired by the findings of Hansen (1998) and Glass and Jacobs (1998).

Cities that are centers of commerce are also important centers for the fashion and glamour industries (Gemperli, 2010), and this explains why all states with large cities have representatives in the website.

\section{Types of modeling that the women accept}

The statements posted by glamour models often reflect interest in working in artistic fields, perhaps because artistic fields are considered more serious and creative than glamour. Many models state that they are comfortable in Fashion and other categories in which work is done clothed, but there are also many that accept categories with artistic nudes, maybe because art and lingerie images are more accepted socially than explicit erotic and sexual images (Evans, Riley, \& Shankar, 2010).

Falsely advertising the types of modeling that they accept would affect these women because the false information would become evident as soon as they were in front of the camera, thus we believe that they mostly tell the truth about modeling categories. While reading posts by photographers in the same website we noticed that they often complained about models not showing up for sessions, causing the photographers an important loss of money and time. Failure to appear may result from last minute insecurity rather than from models lying about what they can do. Nevertheless, a more detailed study of individual cases would be needed to reliably triangulate the models' statements.

\section{Types of modeling that the women reject}

The fact that many models accepted some degree of nudity but some specifically rejected being photographed in sexually explicit activities suggests that they 
want to keep themselves clearly separated from the more socially rejected role of "porn models" and that they sometimes are offered this kind of work (see Attwood, 2007). Erotic images are used frequently in the media to sell many types of products, and among these, glamorous images of women can merge with more openly sexual images, so we suspect that with time some models could move from glamour to more sexual images, while others probably remain in the glamour category for their whole career. Such cases have been documented in the series "Shot by Kern" (www.vice.com/shot-by-kern/). The two least accepted modeling types were Bondage and Web. Bondage implies modeling physically restrained in openly sexual poses, Web modeling is often associated with sex and low quality images (Edelman, 2013). Of course there are models interested in this market but they are not expected to have their profiles in glamour sites.

\section{Comments on work, motivation and limits}

While some research has claimed that people with negative self presentation want to receive negative appraisals (Swann, Wenzlaff \& Tafarodi, 1992), other studies found that negative appraisals are received with depression or even violence (Stucke \& Sporer, 2002; Kwang \& Swann, 2010). However, such results are not necessarily contradictory because they apply to different samples. In any case, we did not find cases of negative self presentation in glamour models. When they choose to publish their profiles, these glamour models are elaborating a self-presentation for their potential clients, who are mostly individual photographers (about 3000 photographers also posted their profiles in GlamourModels). Models focus on the two most desirable characteristics in the profession: attractiveness and reliability. We suspect that most of them "embellish" their self presentation in the website by using their most flattering photographs and by stating how enthusiastic and reliable they are.

The tendency to emphasize behavior over physical appearance can be explained because all profiles include photographs, making further descriptions redundant, and because they seem to be aware of the need for reliable models in a field in which models not showing up for photographic session are a frequent complaint (Rooney, 2010; Nicholas, 2012). Apparently, women who posted their profiles at the site know that current glamour modeling often implies some degree of nudity and most included nude modeling among the accepted work types. In several western societies the media are increasingly accepting depictions of the nude human body and women are free to choose this line of work (Solomon et al., 1992; Winship, 2000; Soley-Beltrán, 2004). We agree with the position expressed by Eklund (2011), who wrote that in the online world today, gender and sexuality are parts of the same phenomenon and should not be studied separately.

Postwar changes in American society led to a culture in which women are no longer limited to the house and can be independent and active outside of the home environment (Winship, 2000). These glamour models are not an exception, often stating that they can travel as required. Like all people who work, glamour models use their minds and bodies to reach goals in their society, despite the fact that the emphasis on the body is criticized by some feminists; maybe glamour modeling can be understood within post-feminist theory, even though there is little agreement about what post-feminism is (Gill, 2008).

The posting of more personal information in websites, as done extensively by celebrities, may create a false sense of intimacy with readers (Marwick \& Boyd, 2011) and while some models do post this type of information, the website in our study only posts information directly related to modeling. Photographs of attractive women may have the same effect on viewers as the real women, including in many cases the natural fantasies of sex (e.g. Perlow, 2011) and this may be a reason why most models refrain from adding much personal information to their pages in Glamour Models. They would be right if they worried about stalkers. However the "possession state" in a digital medium is different because it is symbolically "reconstituted" (Schau \& Gilly, 2003).

The anonymous and textual nature of cyberspace allows users to explore certain sides of their personalities more extensively, or even invent virtual personae quite different from their real life personalities (Papacharissi, 2002). Maybe the glamour model's self presentation in this website includes some idealization, but in any case is consistent with the expectation of their target: the photographers who may hire them.

\section{Studies and contracts}

Most models do not mention having university degrees or other higher studies in their profiles, and this agrees with the practice of modeling during the student years to help finance their education. However, the mean age of these models was close to 28 years so they were expected to have finished college and university studies. We do not know if the reason that so few mentioned degrees in the profiles was that they did not feel it was pertinent, or that they did not actually have degrees. 
Considering that the typical fashion runway model earns $\$ 30$ hour but signs enough contracts to make $\$ 30000$ - \$60 000/year (www.fashion-schools.org/fashion-model.htm; March 2, 2012), it can be expected that these women would prefer fashion modeling to glamour, because even though glamour pays more per hour (\$50-\$80: www.modelsanctuary.com/html/guidelines. html, March 2, 2012), there are few contracts per year and a typical glamour model is estimated to earn only \$2 400 per year (see Results). Biometric data suggest that the women profiled in GlamourModels have weights and waist-to-hip ratios that are close to the fashion requirements of $54,4 \mathrm{~kg}$ maximum and near 0,7 ratio, but they are prevented from entering fashion modeling by their height (their mean height is $9 \mathrm{~cm}$ under the minimal $1,77 \mathrm{~cm}$ required for fashion models, http://models.com/ help/005-what_are_requirements.html).

Their estimated average income of $\$ 2400$ per year from modeling is not enough to cover the expenses of a person for a year in the USA (\$17000; http://www2. ed.gov/about/offices/list/ope/trio/incomelevels.html). Thus, glamour modeling must be a supplement to their main source of income, which was not considered in this study because most models do not mention it in their profiles.

In conclusion, these glamour models are women in their late twenties who probably would prefer work in the fashion industry but cannot work as fashion models. They find in glamour modeling a supplementary source of income that can be pursued along with other activities and that pays a high fee.

\section{ACKNOWLEDGMENTS}

We thank Feona Attwood (Sheffield Hallam University, UK); Adrienne Evans (Coventry University, UK), and two anonymous reviewers for their valuable comments on an earlier draft; Andrea Induni for assistance with data transcription, Sally Horn for correcting the abstract's grammar and Sergio Aguilar for drafting the maps.

\section{REFERENCES}

Attwood, F. (2007). No Money Shot? Commerce, Pornography and New Sex Taste Cultures. Sexualities, 10(4), 441-456.

Bem, D. J. (1967). Self-Perception: An Alternative Interpretation of Cognitive Dissonance Phenomena. Psychological Review, 74, 183-200.
Bock, G. (1983). Racism and Sexism in Nazi Germany: Motherhood, Compulsory Sterilization, and the State. Signs, 8(3), 400-421.

Buss, D. (2009). How Can Evolutionary Psychology Successfully Explain Personality and Individual Differences? Perspectives on Psychological Science, 4(4), 359- 366.

Coy, M. (2009) Milkshakes, lady lumps and growing up to want boobies: how the sexualisation of popular culture limits girls' horizons. Child Abuse Review, 18(6), 372-383.

Coy, M., \& Garner, M. (2010). Glamour modelling and the marketing of self-sexualization. Critical reflections. International Journal of Cultural Studies, 13 (6), 657-675.

Darwin, C. (1872). The expression of the emotions in man and animals. London, England: John Murray.

Edelman, J. (2013). What Are The Different Types of Modeling? Allentown, Pennsylvania: Joe Edelman Photographics, Inc. Retrieved from www.joeedelman.com/modeling-industry/ what-are-the-different-types-of-modeling/

Eklund, L. (2011). Doing gender in cyberspace: The performance of gender by female World of Warcraft players. Convergence, 17(3), 323-342.

Evans, A., Riley, S., \& Shankar, A. (2010). Technologies of Sexiness: Theorizing Women's Engagement in the Sexualization of Culture. Feminism Psychology, 20 (1), 114-13.

Frith, H., Raisborough, J., \& Sisterhood, O. K. (2010). Sexuality and the space of the benign in makeover TV. International Journal of Cultural Studies, 13(5), 471-489.

Garner, D.M., Garfinkel, P.E., Schwartz, D., \& Thompson, M. (1980). Cultural Expectations of Thinness in Women. Psychological Reports, 47, 483-491.

Gemperli, N. (2010). Fashion World Mapper: Your City on the Trend Radar. M Sc. Thesis, University of the Arts, Zurich, Switzerland.

Gill, R. (2008). Empowerment/Sexism: Figuring Female Sexual Agency in Contemporary Advertising. Feminism \& Psychology, 18, 35-60.

Goffman, E. (1959). The Presentation of Self in Everyday Life. New York: Anchor Books.

Glass, J., \& Jacobs, J. (1998). Childhood Religious Conservatism and Adult Attainment among Black and White Women. Social Forces, 84(1), 555-557.

Hansen, C. (1998). Long-term effects of religious upbringing. Mental Health, Religion \& Culture, 1(2), 91-111.

Kościński, K. (2013) Attractiveness of women's body: body mass index, waist-hip ratio, and their relative importance. Behavioral Ecology, 24(4), 914-925.

Kwang, T., \& Swann, W.B. (2010). Do People Embrace Praise Even When They Feel Unworthy? A Review of Critical Tests of Self-Enhancement Versus Self-Verification. Personality and Social Psychology Review, 14(3), 263-280. 
Marlowe, F., \& Wetsman, A. (2001). Preferred waist-to-hip ratio and ecology. Personality and Individual Differences, 30, 481-489.

Marwick, A., \& Boyd, D. (2011). To See and Be Seen: Celebrity Practice on Twitter. Convergence, 17(2), 139-158.

Monge-Nájera, J., \& Vega, K. (2011). Self view of women's bodies and characteristics in early glamour website models. Cuadernos de Investigación UNED, 3(1), 45-51.

Nicholas, A.K. (2012). True Confessions of Nude Photography. San Francisco, California: Double Ink International.

Papacharissi, Z. (2002). The Presentation of Self in Virtual Life: Characteristics of Personal Home Pages. Journalism \& Mass Communication Quarterly, 79(3), 643-660. doi: $10.1177 / 107769900207900307$

Paulhus, D. L., Bruce, M. N., \& Trapnell, P. D. (1995). Effects of SelfPresentation Strategies on Personality Profiles and their Structure. Personality and Social Psychology Bulletin, 21(2), 100-108. doi:10.1177/0146167295212001

Perlow, S. (2011). On production for digital culture: iPhone Girl, electronics assembly, and the material forms of aspiration. Convergence, 17(3), 245-269.

Rooney, K. (2010). Live Nude Girl:My Life as an Object. Fayetteville, Arkansas: University of Arkansas Press.

Schifter, S. (1999). La casa de Lila. New York, N.Y.: The Haworth Hispanic and Latino Press.

Schlenker, B. R. (1975). Self-presentation: Managing the impression of consistency when reality interferes with self-enhancement. Journal of Personality and Social Psychology, 32(6), 1030-1037. doi:10.1037/0022-3514.32.6.1030

Schau J., H., \& Gilly, M. (2003). We Are What We Post? SelfPresentation in Personal Web Space. Journal of Consumer Research, 30(3), 385-404.
Soley-Beltran, P. (2004). Modeling Femininity. European Journal of Women's Studies, 11: 309-326.

Solomon, M., Ashmore, R.D., \& Longo, L.C. (1992). The beauty match-up hypothesis: congruence between types of beauty and product image in advertising. Journal of Advertising, 21(4), 23-34.

Swann, W.B., Wenzlaff, R.M., \& Tafarodi, R.W. (1992). Depression and the search for negative evaluations: More evidence of the role of self-verification strivings. Journal of Abnormal Psychology, 101(2), 314-317.

Stucke, T.S., \& Sporer, S.L. (2002). When a Grandiose Self-Image Is Threatened: Narcissism and Self-Concept Clarity as Predictors of Negative Emotions and Aggression Following Ego-Threat. Journal of Personality, 70(4), 509-532.

Tovée, M. J., Mason, S.M., Emery, J.L., McCluskey, S.E., \& CohenTovée, E.M. (1997). Supermodels: stick insects or hourglasses? The Lancet, 350(9089),1474 - 1475.

Turner, E. (2012). About Me: A narrative analysis of self-presentation in women's online dating profiles. M.Sc. Thesis, University of Guelph, Ontario, Canada.

Winship, J. (2000). Women outdoors, Advertising, controversy and disputing feminism in the 1990s. International Journal of Cultural Studies, 3(1), 27-55.

Editor: ZAIDETT BARRIENTOS 